\title{
Psikolojik Danışmanların Duygusal Emek Stratejilerinin Tükenmişlik Düzeyleri Üzerindeki Etkisinin İncelenmesi
}

DOI: $10.26466 /$ opus. 968874

\author{
* \\ Ümit Kalay* - Merve Mamac1 ${ }^{* *}$
}

* Uzm. Psk., İstanbul Kent Üniversitesi, Lisansüstü Eğitim Enstitüsü, İstanbul/Türkiye

E-Posta: umitkalay1@gmail.com ORCID: 0000-0002-7875-4000

** Dr., Fenerbahçe Üniversitesi, İktisadi İdari ve Sosyal Bilimler Enstitüsü, İstanbul/Türkiye Öz

E- Posta: merve.mamaci@fbu.edu.tr $\quad$ ORCID: 0000-0001-7882-3670

Bu çalı̧mada, aktif iş yaşamı olan psikolojik danışmanların kullandığı duygusal emek stratejileri ile tükenmişlik ve alt boyutları arasındaki ilişkiler incelenmiştir. Araştırmaya İstanbul ilinde aktif çalışma yaşamı olan 294 psikolojik damışman katılmıştır. Araştırmanın verileri Demografik Bilgi Formu, Duygusal Emek Ölçeği ve Psikolojik Danışman Tükenmişlik Ölçeği kullanılarak elde edilmiştir. Elde edilen bulgular; duygusal emek alt boyutu olan yüzeysel rol yapma ile psikolojik danışman tükenmişliği ve alt boyutlar arasında anlamlı ve pozitif yönde bir ilişki olduğunu ortaya koymuştur. Diğer bir duygusal emek stratejisi olan doğal duygular ile psikolojik danışman tükenmişliği ve alt boyutlarn ile arasında anlaml ve negatif yönde bir ilişki olduğu saptanmıştır. Ayrıca, derin rol yapma ile psikolojik danışman tükenmişliğinin yetersizlik alt boyutu arasında anlamlı ve pozitif bir ilişki tespit edilmiştir. Buna karşın, derin rol yapma boyutu ile psikolojik danışman tükenmişliği ve diğer alt boyutlar arasinda anlamlı bir ilişkinin bulunmadığı görülmüştür. Araştırmanın sonuç bölümünde, bulgular alan yazın çerçevesinde incelenerek, gelecek çallşmalar için öneriler sunulmuştur.

Anahtar Kelimeler: Psikolojik Danışman, Duygusal Emek, Tükenmişlik. 


\title{
Investigation of the Effects of Psychological Counselors' Emotional Labor Strategies on Burnout Levels
}

\begin{abstract}
In this study, the relationship between emotional labor strategies used by psychological counselors, burnout levels and its sub-dimensions were examined. 294 psychological counselors with active working life in Istanbul participated in the research. The data of the study were obtained by using the Demographic Information Form, the Emotional Labor Scale and the Psychological Counselor Burnout Scale. Results showed that; there is a significant and positive relationship between the emotional labor subdimension surface acting and psychological counselor burnout and its sub-dimensions. It has been determined that there is a significant and negative relationship between genuine feelings and psychological counselor burnout and its sub-dimensions. In addition, a significant and positive relationship was found between deep acting and the inadequacy sub-dimension of psychological counselor burnout scale. On the other hand, it was observed that there was no significant relationship between deep acting and psychological counselor burnout and other sub-dimensions. At the end of the research, the findings were examined within the framework of the literature and suggestions were presented for future studies.
\end{abstract}

Key Words: Renewable Energy, Electrical Energy, ARDL Boundary Test, Simulation. 


\section{Giriş}

Duygusal emek ve tükenmişlik literatür tarafından sıklıkla incelenen konular arasında yer almaktadır. Duygusal emek kavramını ilk kez literatüre kazandıran Hochschild (1983) duygusal emek stratejilerinin kullanılabilmesi için üç şartın sağlanması gerektiğini dile getirmiştir. Bu şartlara göre; (1) çalışan kişiler ve hizmet alanlar arasında yüz yüze görüşme ve sesli bir iletişimin bulunması, (2) çalışanın hizmet alan kişiye karşı duygusal bir durum (minnettarlık ya da korku gibi) üretmesi, (3) çalışanların duygulanımı üzerinde gözetim ya da eğitim yoluyla dışarıdan etki eden bir kontrol mekanizması olması gerekmektedir. Psikolojik danışmanlar bahsedilen kriterleri karşılamaktadır ve bu sebepten bu araştırmanın örneklemini oluşturmaktadırlar.

Türkiye'deki psikolojik danışmanların \%92'si eğitim sektöründe çalışmaktadır. Eğitim sektöründe psikolojik danışmanların, öğrencilerin ihtiyaçlarını karşılamak ve problemlerini çözmek için sistematik bir şekilde bireysel ya da gruplara yönelik rehberlik ve psikolojik danışmanlık hizmeti sağlaması beklenmektedir. Psikolojik danışmanların iş yüklerinin fazla oluşu ve meslek rollerindeki belirsizlikler gibi durumların psikolojik danışmanlarda tükenmişliğe neden olabileceği dile getirilmektedir (Owen ve Güneri, 2015). Tükenmişlik çalışanların iş hayatını ve sağlıklarını olumsuz etkileyen bir durum olarak ortaya çıkmaktadır (Maslach ve Leiter, 2017). Bu açıdan bakıldığında psikolojik danışmanların tükenmişlik düzeylerinin saptanması önem kazanmaktadır.

Türkiye'deki ve dünyadaki alan yazın incelendiğinde duygusal emek ve tükenmişlik arasındaki ilişkinin öğretmenler (Yin, Huang ve Chen, 2019), turizm çalışanları Wang (2020), futbol antrenörleri (Tolukan, 2019) gibi farklı gruplarda incelendiği görülmektedir. Vasquez (2020) ise psikolojik danışmanlarda duygusal emek ve tükenmişlik arasındaki ilişki üzerine bir çalışma bulunmaktadır. Ancak Türkiye'de psikolojik danışmanlarda duygusal emek ve tükenmişlik ilişkisinin incelendiği bir araştırmaya rastlanmamıştır.

Bu sebeplerden, mevcut çalışmada Türkiye'de aktif çalışma yaşamı olan psikolojik danışmanların duygusal emek stratejilerinin ve tükenmişlik düzeylerinin tespiti hedeflenmiştir. Ayrıca duygusal emek 
stratejileri ile tükenmişlik ve alt boyutları arasındaki ilişkilerin incelenmesini amaçlanmıştır.

\section{Kavramsal Çerçeve}

Hochschild (1983) duygusal emeği, çalışanların örgütsel ve mesleki beklentileri karşılamak için gereken bedensel ifadeleri yaratmak amacıyla duyguların düzenlemesi olarak tanımlamıştır. Çalışanlar, hizmet alan kişiler ile olan iletişimlerinde bedensel ifadeler ve mimikler göstermektedirler. Duyguların düzenlenmesi çalışanların uygun ifadeleri göstermelerini sağlar. Duyguların yönetilmesinde harcanan bu çabayı Hochschild $(1979 ; 1983)$ bir çeşit rol yapma olarak tanımlamıştır.

Hochschild (1983) duygusal emeği yüzeysel rol yapma ve derin rol yapma boyutlarıyla açıklamaktadır. Yüzeysel rol yapma alt boyutu duygunun bedensel gösteriminin düzenlenmesini ifade etmektedir. Kişi gerçekte deneyimlediği duygudan farklı olarak bedensel bir gösterimde bulunur. Duygunun bu şekilde farklı gösterimi bireyde duygusal çelişkiye sebep olmaktadır. İkinci boyut olan derin rol yapmada ise kişilerin bilinçli bir çaba ile hissedilen duyguyu değiştirmesi olarak tanımlanmaktadır. Bu şekilde bireyler uygun duyguyu ifade etmeyi amaçlarlar.

Ashforth ve Humphrey (1993) duygusal emeğin her zaman duyguların yönetimine ihtiyaç duymadığını savunmuştur. Bu sebeple yüzeysel rol yapma ve derin rol yapma boyutlarının yanına doğal duygular boyutunu ilave etmişlerdir. Bu bakış açısına göre çalışanlar kendi içten doğal duyguları ile gösterim kurallarına uygun davranışı sergileyebilmektedir.

Morris ve Feldman (1996) duygusal emeği, örgütsel bağlamda duyguların kişilerarası iletişimde uygun bir şekilde gösterimi için gereken çaba, planlama ve kontrol olarak tanımlamışlardır. Yazarlar, örgütsel beklentilerin çalışanların duyguları ile uyumlu olsa bile duyguların sergilenmesinde belli bir miktar gayret sarf edileceğini belirtmişlerdir, çünkü hissedilen duygunun uygun şekilde ifade edilmesi gerekmektedir. Bir diğer deyişle doğal duyguyu sergilemek de çaba gerektirmektedir.

Grandey (2000) duygusal emeği örgütsel amaçlara ulaşmak için duyguların ve duyguların ifade ediliş biçimlerinin düzenlenmesi olarak 
tanımlamıştır. Yazar, duygu düzenleme sürecinin öncül odaklı (antecedent-focused) duygu düzenleme ve tepki odaklı (response-focused) duygu düzenleme (Gross 1998'den akt. Grandey, 2000) şeklinde gerçekleştirilebileceğini öne sürmektedir. Öncül odaklı duygu düzenlemede, kişiler duygunun öncülü olan durumu ya da durumun algısını değiştirmektedir. Durumu değiştirmek için çalışanlar mümkünse ortamı terk edebilir ya da iş ortamlarını seçebilir koşullarda olmalıdır. Durum algısının değişimi ise dikkat dağıtımı (attentional deployment) ve bilişsel değişim (cognitive change) yöntemleriyle gerçekleşmektedir (Grandey, 2000). Dikkat dağıtımı yönteminde kişi dikkatini farklı bir yere yöneltebilir. Bilişsel değişim ise olayın yeniden değerlendirildiği, yorumlandığı bir yöntemdir. Çalışan yaşanan duruma farklı anlamlar yükleyerek, durumun duygusal etkilerini azaltmaya çalışır (Lazarus 1991'den akt. Grandey, 2000). Çalışanda duruma yönelik gerçekleşen bilişsel değişim, derin rol yapmaya hizmet eden bir yöntemdir.

Tepki odaklı duygu düzenlemede, birey durumu ya da duygusunu değiştirmeye değil duygunun ifade ediliş şeklini değiştirmeye odaklanmıştır. Bu şekilde kişi duruma tepkisini ya da duygu gösterimini daha uygun hale getirmeye çalışmaktadır. Bu açıdan yüzeysel rol yapma ile benzerlikler taşıdığı dile getirilmiştir (Grandey, 2000).

Görüldüğü üzere çalışanlar iş ortamında hizmet alan kişileri memnun etmek ve işveren beklentilerini karşılamak amacıyla birçok rol üstlenmektedir. Bu roller çalışanlar için belirli derecede zorluğu ve baskıyı beraberinde getirmektedir. Bu durum çalışanların yorgunluk, öfke, hayal kırıklığı, yetersizlik ve başarısızlık hissi yaşamalarına neden olmaktadır. Tükenmişlik, bireylerin deneyimledikleri bu yaşantıların bir sonucudur (Maslach ve Jackson, 1981; Maslach ve Goldberg, 1998).

Tükenmişlik kavramı, çok farklı görüşle ve yaklaşımla açıklanmaya çalışılmıştır ve tükenmişliğin standart bir tanımı olmadığı görülmektedir (Maslach, Schaufeli ve Leiter, 2001; Maslach ve Leiter, 2017). Örneğin Kesler (1990) tükenmişliği, düşük motivasyon ve enerjiye sebep olan; inancın, tutkunun ve başkalarına yardımcı olma isteğinin yitip gittiği ve bunların yerini hüsranın, hissizliğin ve yalnızlık algısının aldığ hali olarak açıklamaktadır. Maslach ve Leiter (2017) ise tükenmişliği; duyguları, tutumları, istekleri ve beklentileri içeren olumsuz bir psikolojik 
deneyim olarak tanımlamaktadır. Bu olumsuz deneyimler sıkıntı, rahatsızlık, düşük işlevsellik ve olumsuz sonuçlarla kendini göstermektedir.

Maslach (1982; 1998) tarafından öne sürülen tükenmişlik modelinde mutabakat bulunmaktadır. Bu modelde tükenmişlik yorgunluk (exhaustion), duyarsızlaşma (depersonalization), kişisel başarısızlık (reduced personel accomplishment) boyutlarını içinde bulunduran bir sendrom olarak ele alınmaktadır.

Yorgunluk, tükenmişliğin en temel boyutu ve en belirgin ifadesi olarak gösterilmektedir. Kişilerin en fazla deneyimlediklerini belirttikleri tükenmişlik boyutudur. Buna bağlı olarak da yorgunluk araştırmacılar tarafından sıklıkla incelenmiştir. İş ortamındaki stresin bir temsili olarak kendini göstermektedir. (Maslach vd., 2001). Bireylerin duygusal olarak bunalmışlı̆̆ ve duygusal kaynaklarının tükenmesi yorgunluk olarak adlandırılmaktadır. Çalışanlar bitkin ve enerjiden yoksun hissetmektedirler. Bu durum fazla iş yükü ve kişisel çatışmaların bir sonucudur (Maslach ve Goldberg 1998).

Duyarsızlaşma tükenmişliğin kişiler arası boyutudur. Çalışanların, hizmet alanlarla duygusuzca ve işlevsel olmayan baş etme şeklidir. Genellikle hizmet veren kişiler yorgunluğun bir sonucu olarak, kendilerini koruma amacıyla kayıtsızlık tepkisini geliştirirler (Maslach ve Goldberg, 1998). Bu bağlamda duyarsızlaşma bireylerin, bilişsel olarak diğer kişiler ile arasına mesafe koyma çabasıdır. Gösterilen bu çabadaki en büyük risk ise hizmet alan kişilerin insani özelliklerinden bağımsız değerlendirilmesidir (Maslach vd., 2001). Lee ve Ashforth (1990) ise duyarsızlaşmayı istenmeyen bir talep veya algılanan tehdide karşı, kişinin kendisini korumak için gösterdiği koruma davranışı olarak ifade etmişlerdir.

Kişisel başarısızlık çalışanların yaşadığı yetersizlik ve verimsizlik hissini ifade etmektedir. Bu kişisel yetersizlik hissi depresyon ve düşük baş etme becerileri ile ilişkilendirilmiştir. Çalışanlar kendilerinin mesleki beklentileri karşılamada ve müşterilerine yardımcı olmada başarısız olduklarını düşünmektedirler. Kişisel başarısızlık tükenmişliğin “kendini değerlendirme" boyutunu temsil etmektedir (Maslach ve Goldberg, 1998). Yorgunluk ve duyarsızlaşma, bireylerin kişisel başarı hissini düşürmektedir (Lee ve Ashforth, 1996). 
İş gerekleri - kaynakları tükenmişlik modeline göre ise tükenmişliğin iş gerekleri ile iş kaynaklarının etkileşiminin sonucunda ortaya çıktığı belirtilmektedir. İş yükü, zaman baskısı gibi iş gerekleri arttıkça yorgunluk ortaya çıkmaktadır. İş güvenliği ve ödül gibi iş kaynaklarının azalması ise işe olan bağlılığın azalmasına neden olmaktadır (Demerouti vd., 2001).

\section{Araştırmanın Modeli ve Hipotezler}

Yüzeysel rol yapma boyutunun genel olarak bireyler üzerindeki olumsuz etkiler ile ilişkilendirildiği görülmektedir. Yoğun gayret gerektiren bu yöntem Kaynakları Koruma Kuramı'na göre, bireylerin kaynaklarının tükenmesine yol açabilmektedir (Hobfall, 1989). Alan yazındaki çalışmalar yüzeysel rol yapmanın, yorgunluğa (Grandey 2003; Zhang, Zhang, Lei, Yue ve Zhu, 2016), iş gücünde azalmaya (Goodwin, Groth, ve Frenkel, 2011; Yalçın, 2010) ve iyi oluş üzerinde olumsuz etkilere (Brotheridge ve Lee, 2002) sebep olabileceği belirtilmiştir. Ayrıca, yüzeysel rol yapma boyutunun işteki stres ile pozitif (Jeung vd, 2018), iş doyumu (Zhang ve Zhu, 2008) ve iş iklimi (Yao vd., 2015) ile negatif bir ilişkisinin bulunduğu belirtilmiştir. Birçok farklı sektörde yapılan çalışmalar yüzeysel rol yapmanın tükenmişlik ve tükenmişliğin boyutları ile pozitif ilişkili olduğunu göstermiştir (Akın vd., 2014; Yılmaz vd., 2015; Zhang ve Zhu, 2008). Bu bilgilerden yola çıkarak, yüzeysel rol yapma boyutu ile psikolojik danışmanların tükenmişliğine ilişkin hipotez aşağıdaki gibidir:

H1: Yüzeysel rol yapma boyutu ile psikolojik danışmanların tükenmişliği arasında anlamlı pozitif yönde ilişki vardır ve yüzeysel rol yapma tükenmişliği yordar.

Alan yazında duygusal emek derin rol yapma boyutunun iş doyumu (Lee ve Chelladurai, 2018) öz yeterlilik ve iş performansı ile pozitif ilişkili olduğu ifade edilmektedir (Hülsheger ve Schewe 2011). Duygusal emek ve tükenmişlik ilişkisinin incelendiği çalışmalarda derin rol yapma boyutunun tükenmişlik ve boyutları ile negatif ilişkili olduğu ortaya konmaktadır (Pervaiz vd., 2019; Wang, 2020). Alan yazında belirtilen bulgulara dayanarak, derin rol yapma boyutu ile psikolojik danışmanların tükenmişliği arasındaki ilişkiye yönelik hipotez aşağıdaki gibidir: 
H2: Derin rol yapma boyutu ile psikolojik danışmanların tükenmişliği arasında anlamlı negatif yönde bir ilişki vardır ve derin rol yapma tükenmişliği yordar.

Duygusal emeğin doğal duygular boyutunun, düşük stres (Karim ve Weisz, 2011), öz yeterlilik (Yin vd. 2017) ve iş doyumu ile (Yin, 2015) pozitif ilişkili olduğu alan yazındaki çalışmalar tarafından ortaya koyulduğu gmrülmektedir. Yapılan araştırmalarda, doğal duygular ile tükenmişlik ve boyutlarının negatif bir ilişkiye sahip olduğu belirtilmiştir (Ma vd., 2020; Tepeci ve Pala 2016; Tolukan, 2019). Alan yazında belirtilen bulgulara dayanarak, doğal duygular boyutu ile psikolojik danışmanların tükenmişliği arasındaki ilişkiye yönelik hipotez aşağıdaki gibidir:

H3: Doğal duygular boyutu ile psikolojik danışmanların tükenmişliği arasında anlamlı negatif yönde bir ilişki vardır ve doğal duygular tükenmişliği yordar.

\section{Yöntem}

\section{Evren ve Örneklem}

Araştırmanın evreni psikolojik danışmanlardan ve örneklemi İstanbul ilinde aktif olarak çalışan 294 psikolojik danışmandan oluşmaktadır.

\section{Veri Toplama Araçları}

Verilerin toplanmasına başlanmadan önce İstanbul Kent Üniversitesi Etik Kurul'undan etik onam alınmıştır. Araştırmanın örneklemi kartopu örnekleme yöntemi ile oluşturulmuştur. Veriler, internet ortamı üzerinden ve araştırmacı tarafından anketin katılımcılara iletilmesi ile toplanmıştır.

Demografik Bilgi Formu: Demografik Bilgi Formu katılımcların sosyodemografik özelliklerini değerlendirmek amacıyla oluşturulan 11 sorudan oluşmaktadır. Form soruları cinsiyet, yaş, ilişki durumu, çocuk sahibi olup olmadıkları, eğitim durumu, meslek, çalıştıkları kurum (kamu-özel), çalışma zamanları (Tam zamanlı- yarı zamanlı), bulundukları kurumda çalışma süreleri ile toplam çalışma süreleri ve çalışılan sektör gibi konuları içermektedir. 
Duygusal Emek Ölçeği: Duygusal Emek Ölçeği'nin orijinal formu Diefendorff, Croyle ve Gosserand (2005) tarafından geliştirilmiştir. Basım ve Beğenirbaş (2012) tarafından ölçeğin Türkçe uyarlaması yapılmıştır. Ölçek 3 boyuttan oluşmaktadır ve 13 madde içermektedir. Bu boyutlar; yüzeysel rol yapma, derin rol yapma ve doğal duygulardır. Bu araştırmada, puanlama sistemi orijinal ölçekte olduğu gibi 5'li likert tipi olarak kullanılmıştır. Ölçeğin toplam Cronbach alfa güvenirlilik katsayısı .78, yüzeysel rol yapma boyutu için .89, derin rol yapma boyutu için .88 ve doğal duygular için .86 olarak tespit edilmiştir.

Psikolojik Danışman Tükenmişlik Ölçeği: Psikolojik Danışman Tükenmişlik Ölçeği'nin orijinal formu Lee, Baker, Cho, Heckathorn, Holland, Newgent, Ogle, Powell, Quinn, Wallace ve Yu (2007) tarafından geliştirilmiştir. Bu ölçeğin Türkçe'ye uyarlanması ise Akın, Şentürk ve Özçelik (2016) tarafından gerçekleştirilmiştir. Psikolojik Danışman Tükenmişlik Ölçeği 5 alt boyuttan oluşan toplam 20 madde içermektedir. Bu alt boyutlar yorgunluk, yetersizlik, olumsuz çalışma koşulları, danışanı değersizleştirme ve özel hayatta bozulmadır. Bu araştırmada, puanlama sistemi orijinal ölçekte olduğu gibi 5'li likert tipi olarak kullanılmıştır. Psikolojik danışman tükenmişlik ölçeğinin toplam Cronbach alfa güvenirlilik katsayısı .87, yorgunluk boyutu için .87, yetersizlik boyutu için .80, olumsuz çalışma koşulları boyutu için .86, danışanı değersizleştirme boyutu için .85 ve özel hayatta bozulma boyutu için .83 olarak tespit edilmiştir.

\section{Verilerin Analizi}

Araştırmada elde edilen veriler SSPS v.27 istatistik programı ile istatistiksel analize tabi tutulmuştur. İstatistiksel analizlere geçilmeden önce katılımcıların verileri uç değerler açısından incelenmiştir. Uç değerler analizi sonucunda 2 katılımcının verileri analizler dışında tutulmuştur. Ölçeklerden alınan puanların dağılımı Kolmogorov-Smirnov ve Shapiro Wilk testleri ile normal dağılım testine tabi tutulmuştur (Duygusal Emek Ölçeği W=.986 p=.006 Psikolojik Danışman Tükenmişlik Ölçeği W=.986 $\mathrm{p}=.005$ ). Tabachnick ve Fidell'in (2013) belirttiği gibi çarpıklık ve basıklık (Skewness-Kurtosis) değerlerinin \pm 1.5 aralığında olup olmadıkları 
incelenmiştir. Ölçeklerden alınan puanların çarpıklık ve basıklık değerlerinin \pm 1.5 aralığında oldukları gözlendikten sonra puanların normal dağılım gösterdiği kabul edilmiş ve istatistiksel analizler parametrik testlerle yürütülmüştür. Değişkenler arasında Pearson korelasyon analizi ile regresyon analizi uygulanmıştır.

\section{Bulgular}

\section{Demografik Bulgular}

Araştırmaya toplam 294 kişi katılmıştır. 238 kişi (\%81) kadın ve 56 kişi (\%19) erkektir, yaşları 23-54 arasında değişmektedir. Araştırmada yer alan psikolojik danışmanların \%50.7' si 23-30 yaş, \%28.9'u 31-40 yaş, \%18'i 4150 yaş aralığında, \%2.4'ü 51 yaş ve üzerindedir. Bu kişilerin \%31.6'sı bekar hiç evlenmemiş, \%5,8'i bekar evlenmiş boşanmış, \%47.3'ü evli, \%13.3'üu partneri olan beraber yaşamayan ve $\% 2$ 'si partneri olan beraber yaşayan kişilerdir. Katılımcıların \% 39.1 çocuk sahibidir. Örneklemi oluşturan kişilerin, \%73.5'i lisans, \%25.9'u yüksek lisans ve \%0.7'si doktora mezunudur. Katılımcıların \%74.8'i psikolojik danışmanlık ve rehberlik, \%15.3'üu psikoloji, \%4.4'ü felsefe ve \%5.4 sosyoloji bölümü mezunudur. Psikolojik danışmanların \%54'ü kamuda, \%45.2'si özel sektörde çalışmaktadır. Ayrıca katılımcıların \%98.3'ü tam zamanlı, \%1.7'si yarı zamanlı çalışmaktadir.

\section{Korelasyon Analizi}

Tablo 3'te araştırmanın yüzeysel rol yapma, derin rol yapma, doğal duygular, tükenmişlik, yorgunluk, yetersizlik, danışanı değersizleştirme ve özel hayatta bozulma değişkenleri arasındaki ilişkiye yönelik korelasyon analizinin sonuçları verilmiştir.

Tablo 1. Araştırmanın Değişkenlerine Yönelik Korelasyon Analizi Bulguları

\begin{tabular}{lllllllll}
\hline & $\mathbf{1}$ & $\mathbf{2}$ & $\mathbf{3}$ & $\mathbf{4}$ & $\mathbf{5}$ & $\mathbf{6}$ & $\mathbf{7}$ & $\mathbf{8}$ \\
\hline 1.YüzeyselRol Yapma & 1 & & & & & & & \\
2.DerinRol Yapma & $.313^{* *}$ & 1 & & & & & & \\
3.Doğal Duygular & $-.356^{* *}$ & .050 & 1 & & & & & \\
4.Tükenmişlik & $.399^{* *}$ & .105 & $-.173^{* *}$ & 1 & & & & \\
5.Yorgunluk & $.260^{* *}$ & .081 & $-.142^{*}$ & $.745^{* *}$ & 1 & & & \\
6.Yetersizlik & $.438^{* *}$ & $.161^{* *}$ & $-.156^{* *}$ & $.577^{* *}$ & $.252^{* *}$ & 1 & & \\
7.Değersizleştirme & $.312^{* *}$ & .105 & $-.236^{* *}$ & $.469^{* *}$ & $.120^{*}$ & $.443^{* *}$ & 1 & \\
8. ÖzelHayatta Bozulma & $.171^{* *}$ & .075 & $-.133^{*}$ & $.744^{* *}$ & $.519^{* *}$ & $.221^{* *}$ & $.264^{* *}$ & 1 \\
\hline${ }^{*}<.05 ; * * * 0<.01$ & & & & & & & &
\end{tabular}


Analizler neticesinde, psikolojik danışmanların yüzeysel rol yapma puanları ile tükenmişlik ölçeği puanları arasında anlamlı ve pozitif ( $\mathrm{r}=.398 ; \mathrm{p}=.001)$ yorgunluk alt boyutu puanları arasında anlamlı ve pozitif $(\mathrm{r}=.260 ; \mathrm{p}=.001)$ yetersizlik alt boyutu puanları arasında anlamlı ve pozitif $(\mathrm{r}=.438 ; \mathrm{p}=.001)$ danışanı değersizleştirme alt boyutu arasında anlamlı ve pozitif ( $\mathrm{r}=.312 ; \mathrm{p}=.001)$ ve özel hayatta bozulma alt boyutu arasında anlamlı ve pozitif $(\mathrm{r}=.171 ; \mathrm{p}=.003)$ ilişki bulunmuştur

Gerçekleştirilen analizler incelendiğinde psikolojik danışmanların derin rol yapma puanları ile tükenmişlik ölçeği puanları arasında anlamlı bir ilişki bulunamamıştır ( $\mathrm{r}=.105 ; \mathrm{p}=.072)$. Ayrıca, derin rol yapma puanları ile yorgunluk puanları arasında anlamlı bir ilişki olmadığı görülmüştür ( $\mathrm{r}=.081 ; \mathrm{p}=.167)$. Bir diğer bulgu ise, derin rol yapma puanları ile yetersizlik puanları arasında anlamlı ve pozitif bir ilişki bulunduğunu göstermektedir ( $\mathrm{r}=.161 ; \mathrm{p}=.006$ ). Derin rol yapma puanları ile danışanı değersizleştirme alt boyutu arasındaki ilişki değerlendirildiğinde anlamlı bir ilişki tespit edilmemiştir. Derin rol yapma boyutu ve özel hayatta bozulma alt boyutu arasındaki ilişki değerlendirildiğinde anlamlı bir ilişki bulunamamıştır ( $\mathrm{r}=.075 ; \mathrm{p}=.200)$.

Psikolojik danışmanların doğal duygular boyutu puanları ile tükenmişlik ölçeği puanları arasında anlamlı ve negatif $(\mathrm{r}=-.173$; $\mathrm{p}=003)$ yorgunluk puanları arasında anlamlı ve negatif $\mathrm{r}=-.142 ; \mathrm{p}=.017$ ) yetersizlik alt boyutu puanları arasında anlamlı ve negatif $(\mathrm{r}=-.156 ; \mathrm{p}=.007)$ danışanı değersizleştirme alt boyutu puanları arasında anlamlı ve negatif $(\mathrm{r}=-.236$; $\mathrm{p}=.001)$ özel hayatta bozulma alt boyutu puanları arasında anlamlı ve negatif bir ilişki bulunmuştur ( $\mathrm{r}=-.133 ; \mathrm{p}=.023)$.

Yüzeysel rol yapma ve doğal duygular boyutlarının psikolojik danışman tükenmişliği üzerindeki yordama gücünü anlamak amacıyla bu değişkenler arasında regresyon analizleri yürütülmüştür.

Tablo 2. Bă̆ımsız Değişken Yüzeysel Rol Yapma ile Bă̆ımlı Değişken Tükenmişlik Arasindaki Regresyon Analizine ait Bulgular

\begin{tabular}{|c|c|c|c|c|c|c|c|c|}
\hline Değişken & R & R2 & B & Bsh & $\beta$ & $t$ & $F$ & $p$ \\
\hline$\overline{\text { Sabit }}$ & & & 31.096 & 1.640 & & 18.965 & & \\
\hline $\begin{array}{l}\text { Yüzeysel Rol } \\
\text { Yapma }\end{array}$ & .398 & .158 & .912 & .123 & .398 & 7.408 & 54.9 & .001 \\
\hline
\end{tabular}


Regresyon analizi sonucunda elde edilen modelin $[\mathrm{F}(1-293)=54.9 ; \mathrm{p}<.01]$ anlamlı olduğu; modelde tükenmişlik bağımlı değiş̧enindeki varyansın \%16'sının bağımsız değişken yüzeysel rol yapma ile açıklandığ1 ( $\mathrm{r}=.398$; r2=.158); yüzeysel rol yapma stratejisinin [t=7.408; $\mathrm{p}<.01]$ tükenmişliği yordadığ

Tablo 3. Bağımsız Değişken Doğal Duygular ile Bağımlı Değişken Tükenmişlik Arasındaki Regresyon Analizine ait Bulgular

\begin{tabular}{lllllllll}
\hline Değişken & $\mathbf{R}$ & $\mathbf{R 2}$ & $\mathbf{B}$ & $\mathbf{B s h}$ & $\boldsymbol{\beta}$ & $\mathbf{t}$ & $\mathbf{F}$ & $\mathbf{p}$ \\
\hline Sabit & \multirow{2}{*}{.173} & \multirow{2}{*}{.030} & 51.287 & 3.058 & & 16.773 & \multirow{2}{*}{9.00} & \multirow{2}{*}{003} \\
Doğal Duygular & & & -.775 & .258 & -.173 & -3.001 & & \\
\hline
\end{tabular}
$p<.01$

Regresyon analizi sonucunda elde edilen modelin $[F(1-293)=9.00$; $\mathrm{p}<.01]$ anlamlı olduğu; modelde tükenmişlik bağımlı değişkenindeki varyansın \%3 ünün bağımsız değişken doğal duygular ile açıklandığı ( $\mathrm{r}=.173$; r2=.030); doğal duyguların [t=-3.001; $\mathrm{p}<.01]$ tükenmişliği yordadığı tespit edilmiştir.

\section{Tartışma ve Sonuç}

Bu çalışma, İstanbul'da aktif çalışma yaşamı olan psikolojik danışmanların duygusal emek stratejileri ile tükenmişlikleri arasındaki ilişkiyi anlamak amacıyla yapılmıştır. Çalışmada yapılan analizler sonucunda yüzeysel rol yapma ile psikolojik danışmanların tükenmişliği ve alt boyutları ile arasında pozitif yönlü bir ilişki bulunduğu tespit edilmiştir. Ayrıca doğal duygular ile tükenmişlik ve alt boyutları arasında negatif yönlü bir ilişki olduğu saptanmıştır. Buna karşın, derin rol yapma davranışı ile tükenmişlik arasında anlamlı bir ilişki tespit edilememiştir.

Yüzeysel rol yapma, gösterilen duygunun hissedilenden farklı olduğu bir duygusal emek stratejisidir. Burada gösterilen çaba iş yükünü arttırmakta ve kişilerde duygusal çelişkiye yol açmaktadır. Bu nedenle tükenmişlik ile ilişkilendirilmiştir (Morris ve Feldman, 1996; Maslach vd., 2001). Bu araştırmada da yüzeysel rol yapmanın, tükenmişlik ve alt boyutları (yorgunluk, yetersizlik, danışanı değersizleştirme ve özel hayatta bozulma) ile pozitif ilişkili olduğu görülmüştür. Alan yazındaki araştırma sonuçları (Lee ve Chelladurai, 2018; Tolukan, 2019) bu açıdan araştırmanın bulgularını desteklemektedir. 
Derin rol yapma ile psikolojik danışmanların tükenmişliği ve tükenmişliğin alt boyutları (yorgunluk, danışanı değersizleştirme ve özel hayatta bozulma) arasında anlamlı bir ilişki bulunamamıştır. Derin rol yapma ile tükenmişlik arasındaki ilişkinin incelendiği araştırma sonuçlarında farklılıklar görüldüğü Yin vd. (2019) tarafından dile getirilmiştir. Buna karşın, derin rol yapma ile yetersizlik alt boyutu arasında ise pozitif bir ilişki tespit edilmiştir. Grandey (2000) derin rol yapma sürecini, öncül odaklı duygu düzenleme ile açıklamış ve bir çaba gerektirdiğini belirtmiştir. Bu nedenle danışmanlık hizmeti sürecinde, durumun ya da durumun algısının değiştirilmesi psikolojik danışmanların yetersizlik hislerini güçlendiren bir faktör olarak görülebilir.

Literatürdeki çalışmalar doğal duyguların tükenmişlik ve alt boyutları ile negatif bir ilişkisinin olduğunu ortaya koymaktadır (Yılmaz vd., 2015; Yin vd., 2019). Doğal duygular, çalışanların duyguları ile örgütsel beklentilerin uyumlu olduğu çalışma ortamlarında ortaya çıkan bir duygu gösterimidir. Bu durum, çalışanların duygularında herhangi bir değişime gerek duymadan, çok daha az çabayla duygularını ifade etmelerine olanak sağlar. Dolayısıyla bu araştırmada elde edilen bulguların, diğer çalışmalarla paralel olduğu söylenebilir.

Psikolojik danışmanların duygusal emek stratejileri ile olan ilişkisini daha iyi anlamak önem taşımaktadır. Öğretmen ve danışman rollerini bir arada bulunduran psikolojik danışmanların rol çatışması yaşadıkları dile getirilmiştir. Ayrıca bu çatışmanın tükenmişlikle bir ilişkisinin bulunduğu saptanmıştır (Bardhoshi vd., 2014; Maor ve Hemi, 2021). Yaşanan çatışmanın, duygusal emek ve duygusal emeğin tükenmişlikle olan ilişkisindeki rolünün ileride yapılacak olan araştırmalarda incelenmesi literatüre katkı sağlayabilir.

Hochschild (1983) tarafından belirtilen duygusal emek koşulları arasında yüz yüze bir iletişimin olması gerekliliğinden bahsedilmiştir. Ancak günümüzde çalışanlar ile hizmet alanlar arasında yüz yüze iletişimin gerçekleşmediği çalışma alanları bulunmaktadır. Bu meslek grupları özelinde yürütülecek bir çalışma ile yüz yüze gerçekleşmeyen iletişimin duygusal emek ve tükenmişlik ilişkisi üzerinde nasıl bir rolünün bulunduğunun araştırılması önem taşımaktadır. 
EXTENDED ABSTRACT

\section{Investigation of the Effects of Psychological Counselors' Emotional Labor Strategies on Burnout Levels \\ * \\ Ümit Kalay- Merve Mamac1 \\ Kent University- Fenerbahce Univesity}

Emotional labor and burnout are among the topics that are frequently examined by the literature. Hochschild (1983), who introduced the concept of emotional labor to the literature for the first time, stated that three conditions must be met in order to mention about emotional labor strategies. These conditions are (1) face-to-face meeting and a voice communication between the employees and the service recipients, (2) the employee produces an emotional state (such as gratitude or fear) towards the service recipient, (3) the affect of employees' should be observed from organization and there must be an effective control mechanism on employees. Psychological counselors meet the mentioned criteria and therefore constitute the sample of this study.

Owen and Güneri (2015) stated that situations such as high workload of psychological counselors and uncertainties in their professional roles may cause burnout in psychological counselors. Burnout emerges as a situation that negatively affects the work life and health of employees (Maslach \& Leiter, 2017). From this point of view, it is important to determine the burnout levels of psychological counselors.

When the literature in Turkey and in the world is examined, it is seen that the relationship between emotional labor and burnout is examined in different populations such as teachers (Yin, Huang, \& Chen, 2019), tourism workers Wang (2020), football coaches (Tolukan, 2019). Vasquez (2020), on the other hand, has a study on the relationship between emotional labor and burnout in psychological counselors. However, no research has been found in Turkey examining the relationship between emotional labor and psychological counselors' burnout.

For these reasons, in the present study, it was aimed to determine the emotional labor strategies and burnout levels of psychological counselors 
who have an active working life in Turkey. In addition, it was aimed to examine the relationships between emotional labor strategies and burnout and its sub-dimensions.

Hochschild (1983) explains emotional labor with surface acting and deep acting dimensions. The surface acting expresses the regulation of the bodily display of emotion. The person makes a bodily representation, different from the emotion he actually experiences. This different display of emotion causes emotional conflict in the individual. The second dimension, deep acting is defined as a person's conscious effort to change the emotion felt. Ashforth and Humphrey (1993) argued that emotional labor does not always require the management of emotions. For this reason, they added the dimension of genuine feelings to the superficial acting and deep acting dimensions. According to this point of view, employees can display behaviors in accordance with the display rules with their own natural feelings.

The concept of burnout has been explained with many different views and approaches, and it seems that there is no standard definition of burnout (Maslach, Schaufeli, \& Leiter, 2001; Maslach \& Leiter, 2017). Maslach and Leiter (2017) on the other hand defines burnout as a negative psychological experience that includes emotions, attitudes, wishes and expectations. These negative experiences are characterized by distress, discomfort, reduced functioning, and negative consequences. In this research, burnout has analyzed through fatigue, feelings of inadequacy, adverse working conditions, devaluation of the client and deterioration in private life.

To test hypothesis, 294 psychological counselors with active work life in Istanbul were participated in this research. The data of the study were obtained by using the Demographic Information Form, the Emotional Labor Scale and the Psychological Counselor Burnout Scale. Results showed that; there is a significant and positive relationship between the surface acting and psychological counselor burnout and its sub-dimensions. It has been determined that there is a significant and negative relationship between genuine feelings and psychological counselor burnout and its subdimensions. In addition, a significant and positive relationship was found between deep acting and the inadequacy sub-dimension of psychological counselor burnout scale. On the other hand, it was observed that there was 
no significant relationship between deep acting and psychological counselor burnout and other sub-dimensions.

It is important to better understand the relationship between psychological counselors and emotional labor strategies. It has been stated that psychological counselors, who have the roles of teaching and counseling together, experience role conflicts. It has also been determined that this conflict has a relationship with burnout (Bardhoshi et al., 2014; Maor \& Hemi, 2021). Examination of the role conflict of psychological counselors in terms of emotional labor and burnout in future studies may contribute to the literature.

It was mentioned that there should be a face-to-face communication between the emotional labor conditions stated by Hochschild (1983). However, today, there are working areas where face-to-face communication does not occur between employees and service recipients. For further research it is important to investigate the role of communication that does not take place face-to-face on the relationship between emotional and burnout, with a study to be carried out specifically for these occupational groups.

\section{Kaynakça/References}

Akın, U., Aydın, İ., Erdoğan, Ç., ve Demirkasımoğlu, N. (2014). Emotional labor and burnout among Turkish primary school teachers. The Australian Educational Researcher, 41(2), 155-169.

Akın, A., Şentürk, L. ve Özçelik, B. (2016). Psikolojik Danışman Tükenmişlik Ölçeğinin Türkçe Formunun geçerlik ve güvenirliği. International Journal Of Eurasia Social Sciences, 7(22), 350-359.

Ashforth, B. E. ve Humphrey, R. H. (1993). Emotional labor in service roles:The influence of identity. Academy of Management Review, 18(1), 88-115.

Basım, H. N. ve Beğenirbaş, M. (2012). Çalışma yaşamında duygusal emek: Bir ölçek uyarlama çalışması. Yönetim ve Ekonomi: Celal BayarÜniversitesi İktisadi ve İdari Bilimler Fakültesi Dergisi, 19(1), 77-90.

Bardhoshi, G., Schweinle, A. ve Duncan, K. (2014). Understanding the impact of school factors on school counselor burnout: A mixed-methods study. Professional Counselor, 4(5), 426-443. 
Brotheridge, C. M. ve Lee, R. T. (2002). Testing a conservation of resources model of the dynamics of emotional labor. Journal of Occupational Health Psychology, 7(1), 57.

Demerouti, E., Bakker, A. B., Nachreiner, F. ve Schaufeli, W. B. (2001). The job demands-resources model of burnout. Journal of Applied psychology, 86(3), 499.

Diefendorff, J. M., Croyle, M. H. ve Gosserand, R. H. (2005). The dimensionality and antecedents of emotional labor strategies. Journal of Vocational Behavior, 66(2), 339-357.

Grandey, A. A. (2000). Emotional regulation in the workplace: A new way to conceptualize emotional labor. Journal of Occupational Health Psychology, 5(1), 95.

Grandey, A. A. (2003). When "the show must go on": Surface acting and deep acting as determinants of emotional exhaustion and peer-rated service delivery. Academy of Management Journal, 46(1), 86-96.

Goodwin, R. E., Groth, M. ve Frenkel, S. J. (2011). Relationships between emotional labor, job performance, and turnover. Journal of Vocational Behavior, 79(2), 538-548.

Hobfoll, S. E. (1989). Conservation of resources: A new attempt at conceptualizing stress. American Psychologist, 44(3), 513.

Hochschild, A. R. (1979). Emotion work, feeling rules, and social structure. American Journal of Sociology, 85(3), 551-575.

Hochschild Arlie, R. (1983). The managed heart: Commercialization of human feeling. Berkeley: University of California Press.

Hülsheger, U. R., ve Schewe, A. F. (2011). On the costs and benefits of emotional labor: a meta-analysis of three decades of research. Journal of Occupational Health Psychology, 16(3), 361.

Jeung, D. Y., Kim, C. ve Chang, S. J. (2018). Emotional labor and burnout: A review of the literature. Yonsei Medical Journal, 59(2), 187.

Karim, J., ve Weisz, R. (2011). Emotional intelligence as a moderator of affectivity/emotional labor and emotional labor/psychological distress relationships. Psychological Studies, 56(4), 348-359.

Kesler, K. D. (1990). Burnout: A multimodal approach to assessment and resolution. Elementary School Guidance ve Counseling, 24(4), 303-311.

Lee, R. T. ve Ashforth, B. E. (1990). On the meaning of Maslach's three dimensions of burnout. Journal of Applied Psychology, 75(6), 743. 
Lee, R. T. ve Ashforth, B. E. (1996). A meta-analytic examination of the correlates of the three dimensions of job burnout. Journal of Applied Psychology, 81(2), 123.

Lee, S. M., Baker, C. R., Cho, S. H., Heckathorn, D. E., Holland, M. W., Newgent, R. A., ... ve Yu, K. (2007). Development and initial psychometrics of the counselor burnout inventory. Measurement and Evaluation in Counseling and Development, 40(3), 142-154.

Lee, Y. H., ve Chelladurai, P. (2018). Emotional intelligence, emotional labor, coach burnout, job satisfaction, and turnover intention in sport leadership. European Sport Management Quarterly, 18(4), 393-412.

Ma, Y., Wang, F. ve Cheng, X. (2021). Kindergarten teachers' mindfulness in teaching and burnout: The mediating role of emotionallabor.Mindfulness, 12(3), 722-729.

Maor, R. ve Hemi, A. (2021). Relationships between role stress, professional identity, and burnout among contemporary school counselors. Psychology in the Schools, 58(8), 1597-1610.

Maslach, C. (1982). Understanding Burnout: Definitional Issues in Analyzing a Complex Phenomenon. W.S. Paine (Ed.), Job Stress and Burnout: Research, Theory andIntervention Perspectives içinde (s.29-40). Beverly Hills: Sage Focus Editions.

Maslach, C. (1998). A multidimensional theory of burnout. Theories of Organizational Stress, 68, 85.

Maslach, C. ve Goldberg, J. (1998). Prevention of burnout: New perspectives. Applied and Preventive Psychology, 7(1), 63-74.

Maslach, C. ve Jackson, S. E. (1981). The measurement of experienced burnout. Journal of Organizational Behavior, 2(2), 99-113.

Maslach, C. ve Leiter, M. P. (2007). Burnout. G. Fink (Ed.), Encyclopedia of Stress içinde (s.368-371). California: Academic Press.

Maslach, C., Schaufeli, W. B. ve Leiter, M. P. (2001). Job burnout. Annual Review of Psychology, 52(1), 397-422.

Maslach, C., ve Leiter, M. P. (2017). Understanding burnout: New models. C. L. Cooper ve J. C. Quick (Ed.), The Handbook of Stress and Health: A Guide to Research and Practice içinde (s.36-56). New Jersey:Wiley Blackwell.

Morris, J. A. ve Feldman, D. C. (1996). The dimensions, antecedents, and consequences of emotional labor. Academy of Management Review, 21(4), 9861010. 
Owen, F. K. ve Güneri, O. Y. (2015). Counseling in Turkey. T. H. Hohenshil, N.E. Amundson ve S.G. Niles (Eds.), Counseling Around the World: An International Handbook içinde (s.293-302). Virginia: American Counseling Association.

Pervaiz, S., Ali, A. ve Asif, M. (2019). Emotional intelligence, emotional labor strategies and satisfaction of secondary teachers in Pakistan. International Journal of Educational Management, 33(4), 721-733.

Tabachnick, B.G. ve Fidell, L.S. (2013). Using multivariate statistics. Boston: Pearson.

Tepeci, M., ve Pala, T. (2016). The effects of job-focused and employee-focused emotional labor on burnout in the hospitality industry inTurkey. Journal of Global Strategic Management, 10(2), 95-105.

Tolukan, E. (2019). Relationship between emotional labor behavior and burnout level of football coaches. International Journal of Higher Education, 8(2), 7-15.

Wang, C. J. (2020). Managing emotional labor for service quality: A cross- level analysis among hotel employees. International Journal of Hospitality Management, 88, 102-396.

Yalçın, A. (2010). Emotional labor: Dispositional antecedents and the role of affective events. (Yayınlanmamış yüksek lisans tezi). Middle East Technical University, Ankara.

Yin, H. (2015). The effect of teachers' emotional labour on teaching satisfaction: Moderation of emotional intelligence. Teachers and Teaching, 21(7), 789810.

Yin, H., Huang, S. ve Lee, J. C. K. (2017). Choose your strategy wisely: Examining the relationships between emotional labor in teaching and teacher efficacy in Hong Kong primary schools. Teaching and Teacher Education, $66,127-136$.

Yao, X., Yao, M., Zong, X., Li, Y., Li, X., Guo, F., ve Cui, G. (2015). How school climate influences teachers' emotional exhaustion: The mediating role of emotional labor. International Journal of Environmental Research and Public Health, 12(10), 12505-12517.

Yilmaz, K., Altinkurt, Y. ve Güner, M. (2015). The relationship between teachers' emotional labor and burnout level. Eurasian Journal of Educational Research, 15(59), 75-90. 
Yin, H., Huang, S., ve Chen, G. (2019). The relationships between teachers' emotional labor and their burnout and satisfaction: A meta-analytic review. Educational Research Review, 28, 100283.

Zhang, Y., Zhang, L., Lei, H., Yue, Y. ve Zhu, J. (2016). Lagged effect of daily surface acting on subsequent day's fatigue. The Service Industries Journal, 36(15-16), 809-826.

Zhang, Q. ve Zhu, W. (2008). Exploring emotion in teaching: Emotional labor, burnout, and satisfaction in Chinese higher education. Communication Education, 57(1), 105-122.

\section{Kaynakça Bilgisi/Citation Information}

Kalay, Ü. ve Mamacı, M. (2021). Psikolojik danışmanların duygusal emek stratejilerinin tükenmişlik düzeyleri üzerindeki etkisinin incelenmesi. OPUS- Uluslararası Toplum Araştırmaları Dergisi, 18(43), 6662-6681. DOI:10.26466//opus.968874. 